BMJ Open

Sport \&

Exercise

Medicine

\title{
Breaking up prolonged sitting with a 6 min walk improves executive function in women and men esports players: a randomised trial
}

Joanne DiFrancisco-Donoghue (D) , ${ }^{1}$ Seth E Jenny, ${ }^{2}$ Peter C Douris, ${ }^{3}$ Sophia Ahmad, ${ }^{4}$ Kyle Yuen, ${ }^{4}$ Tamzid Hassan, ${ }^{4}$ Hillary Gan, ${ }^{4}$ Kenney Abraham, ${ }^{4}$ Amber Sousa ${ }^{4}$

To cite:

DiFrancisco-Donoghue $\mathrm{J}$, Jenny SE, Douris PC, et al. Breaking up prolonged sitting with a 6 min walk improves executive function in women and men esports players: a randomised trial. BMJ Open Sport \& Exercise Medicine 2021;7:e001118. doi:10.1136/ bmjsem-2021-001118

- Additional supplemental material is published online only. To view, please visit the journal online (http://dx.doi. org/10.1136/bmjsem-2021001118).

Accepted 5 July 2021

\section{ABSTRACT}

Objective The effect of prolonged sitting on executive function and performance in competitive esports players are unknown. This study aimed to evaluate executive function following a 6 min bout of walking or rest during prolonged gaming in competitive esports players.

Methods 12 men and 9 women completed three separate 2-hour gaming session days assigned in randomised order consisting of a 6 min walk break, 6 min rest break and continuous before and after each session. Postintervention participant exit survey data were also collected.

Results The walk condition produced a significantly faster mean solution time $(7613.6 \pm 3060.5 \mathrm{~min}, \mathrm{p}=0.02)$ and planning time $(5369.0 \pm 2802.09, p=0.04)$ compared with the resting condition $(9477 \pm 3547.4 ; 6924 \pm 3247.7)$ and continuous play (8200.0 $\pm 3031.6 ; 5862.7 \pm 2860.7)$. The rest condition resulted in the slowest mean solution time (9477.0 \pm 3547.4$)$ and planning time $(6924.0 \pm 3247.7)$, with the continuous play resulting in a faster mean solution time $(8200.1 \pm 3031.6)$ and planning time $(5862.7 \pm 2860.7)$ than the rest condition. There was no impact on game performance in any of the conditions. However, over $70 \%$ of participants felt that the walk break improved esports performance.

Conclusions Reducing sit time and breaking up prolonged sitting have acute and chronic health benefits. This study provides evidence that a 6 min walking break in the middle of 2 hours of gameplay allows gamers to have these health benefits while improving processing speed and executive function.

Trial registration number NCT04674436.

\section{INTRODUCTION}

(c) Author(s) (or their employer(s)) 2021. Re-use permitted under CC BY-NC. No commercial re-use. See rights and permissions. Published by BMJ.

For numbered affiliations see end of article.

Correspondence to Dr Joanne DiFranciscoDonoghue; jdonoghu@nyit.edu
Video gameplay is harmonious with prolonged bouts of sitting. Although players are seated for prolonged periods and do not experience the physical demands that are seen in conventional sports, competing in video games (ie, esports) can be quite physically and mentally demanding in other ways. Players can perform up to 500 actions per minute (ie, keyboard or mouse inputs) while simultaneously focusing at a level of attention

\section{Key messages}

What is already known

- Esports players are required to sit for prolonged bouts in order to practice and compete.

- Prolonged sitting may impair executive function and can have dangerous health implications in esports players as young as 12 years old.

- Many preventive measures are not well accepted or practised by esports players, coaches or stakeholders across all levels of competition.

What are the new findings

- A light-intensity 6 min walking break following an acute 1-hour session of competitive gaming improves executive function and processing speed in competitive players.

- A resting 6 min break following 1-hour acute session of competitive gaming decreased executive function speed in players.

- Over $70 \%$ of highly competitive gamers who participated preferred the walking break and reported it 'positively helped' them compared with a resting break.

that results in significant cognitive stress and high variance of physiological parameters. ${ }^{1-4}$ In conjunction with the cognitive stress, players may suffer from the corresponding harmful health effects of prolonged sitting. These include acute health risks such as deep vein thrombosis (DVT), which can be lifethreatening if the thrombosis travels to the lungs and creates a pulmonary embolism (PE) ${ }^{5-7}$ Aside from the acute health risks, the chronic health effects of repeated prolonged sitting are correlated with cardiometabolic risk factors and early mortality. ${ }^{89}$

In addition, prolonged sitting acutely disrupts cerebral blood flow and may reduce oxygen supply to the brain. ${ }^{10}$ This disruption in neuronal metabolism can lead to mental fatigue, impaired cognition and reduced 
executive function. ${ }^{11-13}$ The relationship between prolonged gaming, executive function and physical breaks has not been thoroughly investigated. Recently, Sousa et al found a decrease in executive function in high-level gamers following 2.5 consecutive hours of competitive gameplay regardless of physical activity levels. ${ }^{11}$

This current study set out to expand on these findings and to evaluate executive function changes following a short active break (6 min walking) as compared with a short passive break (6 min resting) in competitive firstperson shooter (FPS) esports players during 2 hours of gameplay. The primary outcome was to evaluate executive function changes. Secondary outcomes included gaming performance as well as players' perceptions.

\section{METHODS}

\section{Design and setting}

This study was a randomised repeated measures experimental design and it was registered on clinicaltrials.gov. Due to the global COVID-19 pandemic, the study was conducted virtually with each participant. This allowed participants to use their own computers. Participants communicated with researchers via Zoom, Google Hangouts, texting and Discord. All of these platforms allow for video and chat communication except for texting through a non-social media platform.

\section{Sample}

Twenty-one participants (12 men and 9women), 20.76 years $(\mathrm{SD}=2.61)$, from seven different countries, participated in this study. Men averaged a body mass index (BMI) of 20 (1.4) and women averaged a BMI of 21.9 (3.4). One subject identified as a transgender woman and had been taking hormone replacement therapy for over 1 year and was included in the analysis as such (figure 1).

Subjects were recruited online via groups and servers on Facebook, Twitter, Twitch and Discord. Twitch is the largest streaming platform for gamers, and Discord allows easy communication through voice, video, chat, text and is very popular among gamers. All subjects

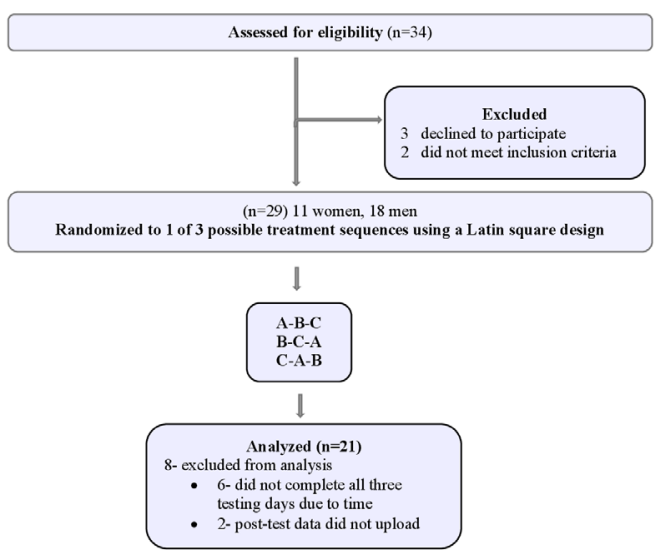

Figure 1 Study flow diagram. signed electronic consent, and study data were collected and managed using REDcap (Research Electronic Data Capture, Vanderbilt University, Nashville, TN) tools hosted at NYIT. REDcap is a secure, web-based application designed to support data capture for research. ${ }^{14}$ Participant inclusion criteria were: (1) women or men 18-30 years of age and (2) play FPS games with over 500 hours of game time. Exclusion criteria were: (1) no competitive FPS ranking, (2) colour blindness and (3) hand injury within the last year or chronic wrist pain (table 1).

\section{Statistical analysis}

IBM SPSS V.27 was used to carry out all statistical analyses. A priori sample size calculations revealed that 20 subjects were required to detect observed differences at a power of $80 \%$. Statistical significance for this study was set at the $\mathrm{p}<0.05$. To compare neuropsychological and esports performance outcomes across our three conditions, we used the General Linear Model in SPSS to compare outcomes among the conditions. Additionally, we examined any potential gender interactions.

\section{Data collection}

Data were collected on 4 separate days with at least 24 hours between each day. Following consent, participants performed a practice test of the online outcome measures to familiarise themselves on the first day. This was followed by 3 intermittent days of participant FPS gameplay that each lasted $120-135$ min ( 2 hours \pm 15 min) each. The 3 days consisted of (1) continuously gameplay for 120-135 min with no break, (2) a 6 min walking break with 60-75 min of gameplay before and after, (3) a 6 min supine resting break with $60-75$ min of gameplay before and after (figure 2). The intervention order was randomised across participants using a Latin square design. ${ }^{15}$ The 15 min window for gameplay was to allow for participants to finish any active game. This was done by texting the subjects $10 \mathrm{~min}$ before the 60 min marker and $10 \mathrm{~min}$ before the $120 \mathrm{~min}$ marker. Subjects were told to finish the current game and text the investigator as soon as the game was finished. This did not impact on our study as all games were able to be completed within the time frame set. Furthermore, subjects were asked to try and maintain a similar diet on all testing days and to eat within the same time frame prior to playing for each testing day. Diets consisted predominantly of small snacks and sandwiches prior to gaming.

The $6 \mathrm{~min}$ break was based on findings by Chrismas $e t a l$, who found a 3 min walking break at 30 min improved attention and executive function. ${ }^{16}$ Breaking up an esports game every $30 \mathrm{~min}$ is not reasonable. Therefore, we chose to break at $60 \mathrm{~min}$ of play using the cumulative break time of $6 \mathrm{~min}$. All participants were required to play using the same FPS game title, same gaming setup and not change any equipment they used in previous sessions. All data were collected within the same time of day across sessions. 
Table 1 Demographic data

\begin{tabular}{|c|c|c|c|}
\hline Men & $n=12$ & Women & $n=9$ \\
\hline Age (SD) & $20(1.4)$ & Age (SD) & $22(3.4)$ \\
\hline Weight (kg) (SD) & $85.7(27.8)$ & Weight (kg) & $66.2(11.8)$ \\
\hline Height (in) (SD) & $70(1.4)$ & Height (in) & $66.1(2.7)$ \\
\hline BMI (SD) & $20(1.4)$ & $\mathrm{BMI}$ & $21.9(3.4)$ \\
\hline Current residence (\%) & & Current residence (\%) & \\
\hline United States & 66 & United States & 56 \\
\hline Netherlands & 8 & Canada & 11 \\
\hline France & 8 & Sweden & 11 \\
\hline England & 18 & Finland & 33 \\
\hline Education level (\%) & & Education level (\%) & \\
\hline High school & 33 & High school & 44 \\
\hline Associates degree & 8 & Associates degree & 0 \\
\hline Current bachelor's student & 33 & Current bachelor's student & 34 \\
\hline Bachelor's degree & 26 & Bachelor's degree & 11 \\
\hline Master's degree & 0 & Master's degree & 11 \\
\hline Ethnicity (\%) & & Ethnicity (\%) & \\
\hline Caucasian & 50 & Caucasian & 67 \\
\hline Asian & 42 & Asian & 22 \\
\hline Prefer not to answer & 8 & Prefer not to answer & 11 \\
\hline Right-handed & 85 & Right-handed & 100 \\
\hline Primary game (\%) & & Primary game (\%) & \\
\hline Overwatch & 33 & Overwatch & 45 \\
\hline Valorant & 33 & Valorant & 11 \\
\hline Team fortress & 9 & Fortnite & 11 \\
\hline Counter strike & 9 & Counter strike & 11 \\
\hline Rainbow six & 9 & Halo & 22 \\
\hline Apex legends & 9 & & \\
\hline Hours played weekly (\%) & & Hours played weekly (\%) & \\
\hline More than 6 & 100 & More than 6 & 67 \\
\hline 5-6hours weekly & 0 & 5-6hours weekly & 22 \\
\hline 3-4 hours weekly & 0 & 3-4 hours weekly & 11 \\
\hline Tournament rankings \% (varies by game) & & Tournament rankings (may va & \\
\hline Top 500 globally & 15 & Top 500 globally & 0 \\
\hline Master & 15 & Master & 33 \\
\hline Platinum & 7 & Platinum & 22 \\
\hline Diamond & 24 & Diamond & 0 \\
\hline Gold & 7 & Gold & 22 \\
\hline Silver 3 & 7 & Silver 3 & 0 \\
\hline Other & 24 & Other & 22 \\
\hline
\end{tabular}

BMI, body mass index.

Day 1

Interested participants were asked to complete an online consent form, demographic form and the International Physical Activity Questionnaire (IPAQ) Long Version ${ }^{17}$ in REDcap. Instructions for baseline completion of executive function measures were administered and completed within 2 days of testing for familiarisation. The online executive function tests were administered through
Millisecond Software (Seattle, Washington) remote psychological testing.

Days 2, 3 and 4

Before testing, each participant was connected to a researcher virtually. On completing each gaming session, participants were asked not to leave the gaming station and immediately take the online tests again. After 


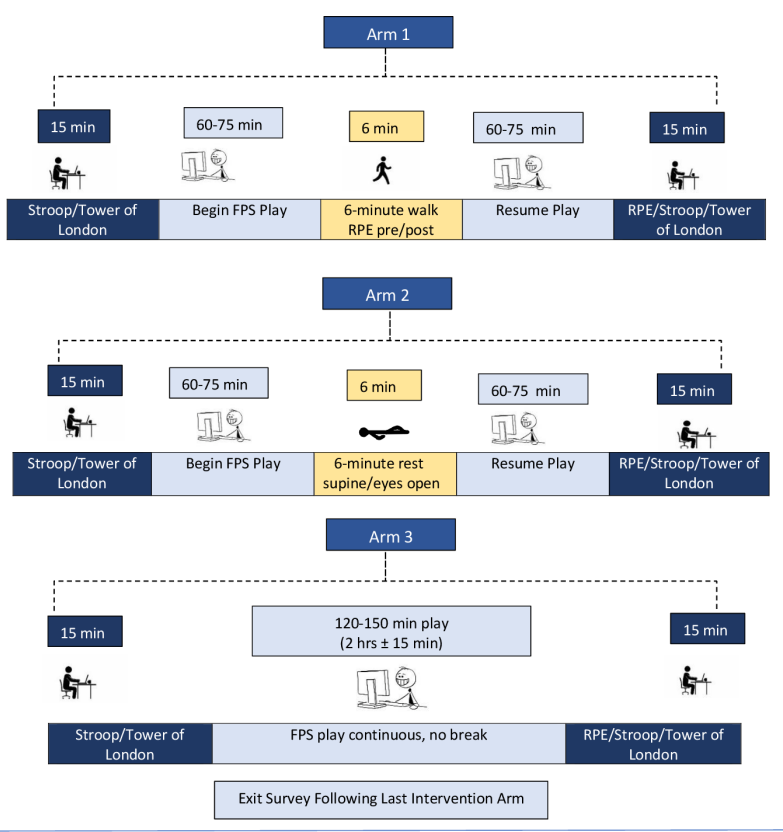

Figure 2 Virtual study protocol. FPS, first-person shooter; RPE, Rating of Perceived Exertion.

completing all three arms, subjects completed a final exit survey through REDcap that focused on perceptions of the effectiveness of each of the three-arm conditions on their gaming performance.

\section{The three arms}

\section{The walking intervention}

Participants were asked to find a place near their gaming setup that they were able to walk for 6 min on a flat surface back-and-forth while holding their smartphone in their hand to hear the investigators' cues. Before gaming, the investigator instructed the participant to open the testing links and to begin the tests. Once the completed tests were confirmed, the participant logged onto their game and told the investigator when they began. At $55 \mathrm{~min}$, the investigator instructed the participant to finish their current game and alert them when they do. The average time before a break was 1 hour and 7 min $(67.4 \pm 7.9 \mathrm{~min})$. Each investigator used the same verbiage: 'You will now get up and walk for 6 uninterrupted minutes. You are to walk briskly but comfortable. I will let you know when you are halfway done. After, I will ask you how hard your effort was while walking using the scale between 6-20 that I show you'. The 6-20 Borg Rating of Perceived Exertion (RPE) Scale was shown to the participant via the video conference screen. The Borg scale is a validated scale to measure how hard a person feels they are working during physical activity and has been validated to correlate heart rate and perceived effort during active video game play. ${ }^{18}$ The participants then returned directly to gaming. At the 55 min marker, they were instructed to alert the investigator when they completed the current game. The average time of the second gaming segment was 1 hour $7 \mathrm{~min}(66.5 \pm 8.3 \mathrm{~min})$. On completion of gaming, RPE was recorded and the number of wins, losses and kill-death ratio (KDR) for each game. Following this, participants were instructed to complete the online executive function tests immediately. KDR is an individual FPS player statistic, equal to the number of opponent 'kills' divided by the number of player 'deaths' recorded across an entire game. A KDR of greater than one indicates more kills were recorded than deaths. For example, a player with 23 kills and 16 deaths would have a KDR of 1.44 for that game.

\section{The supine rest intervention}

The same procedures used for the walking intervention were followed for the rest intervention, except instead of walking, the participants laid supine for $6 \mathrm{~min}$ with their eyes open next to their gaming area. The reason participants kept their eyes open was to avoid any rest of the eyes that was not given while doing the 6 min walk break. The first gaming segment before rest averaged 1 hour $3 \mathrm{~min}(63.2 \pm 3.9)$, while the subsequent postrest gaming session averaged 1 hour 2 min (62.3 \pm 4.7$)$.

\section{The continuous gaming session}

Participants were asked to complete the executive functioning measures before playing. Following $115 \mathrm{~min}$, they were to complete their current game. The average gaming time during continuous gaming was 2 hours $5 \min (125.3 \pm 6.0 \mathrm{~min})$.

\section{Outcome measurements}

Colour word Stroop with keyboard (Stroop)

The colour word Stroop is a measure of reaction time, speeded inhibitory control and set switching. ${ }^{19}$ The Stroop test was administered online via the Inquisit Lab software, developed by Millisecond Software (Seattle, Washington).

\section{The Tower of London}

The Tower of London test is a neuropsychological instrument that measures the executive functioning area of planning and non-verbal problem-solving abilities. ${ }^{20}$

\section{Exit survey}

On completing all three intervention arms, participants were surveyed on how they believed each impacted their gaming performance. As prescribed by Creswell and Poth,$^{21}$ open-response data were first open coded to find primary themes. Then, data were reanalysed via axial coding and finally selective coding to finalise the major themes through cross-referencing the interrelationships of the major coded primary themes.

\section{Patient and public involvement}

Patients and/or the public were not involved in the design, or conduct, or reporting, or dissemination plans of this research.

\section{RESULTS}

For neuropsychological outcomes, there were significant differences among conditions for the Tower of London 
means solution time and planning time. For both of these outcomes, the walking condition produced the fastest solution time $(7613.6 \pm 3060.5 \mathrm{~min}, \mathrm{p}=0.02)$ and planning time $(5369.0 \pm 2802.1, \mathrm{p}=0.04)$. The continuous play condition produced the second-fastest solution time (8200.1 $\pm 3031.6 \mathrm{~min})$ and planning time $(5862.7 \pm 2860.7$ min) and the resting condition produced the slowest solution time $(9477.0 \pm 3547.4 \mathrm{~min})$ and planning time (6924.0 $\pm 3247.7 \mathrm{~min})$. There were no significant differences among conditions for neuropsychological outcome variables, including Tower of London total accuracy,
Stroop reaction time and Stroop proportion correct. Ratings of perceived exertion were not significantly different between conditions $(\mathrm{p}=0.08)$. The percentage of esports games won was not significantly different across conditions $(\mathrm{p}=0.6)$, nor was KDR $(\mathrm{p}=0.8)$. There were no significant interactions by participant gender for any of the analysed dependent variables (table 2).

\section{Exit survey findings}

As seen in table 3 , over $70 \%$ of participants perceived that the $6 \mathrm{~min}$ walk break 'positively helped' gaming

Table 2 Outcome measurements following a walking break, resting break and continuous play

\begin{tabular}{|c|c|c|c|c|c|}
\hline \multirow[b]{2}{*}{ Outcome variable } & \multirow[b]{2}{*}{ Women $(n=9)$} & \multirow[b]{2}{*}{ Men $(n=12)$} & \multirow[b]{2}{*}{ Group (n=21) } & \multirow{2}{*}{$\begin{array}{l}\text { P value } \\
\text { By group }\end{array}$} & \multirow{2}{*}{$\begin{array}{l}\mathbf{P} \text { value } \\
\text { Gender } \\
\text { interaction }\end{array}$} \\
\hline & & & & & \\
\hline Total accuracy & & Number correc & & & \\
\hline Walk & $34.2(1.1)$ & $33.4(2.3)$ & $33.8(1.9)$ & & \\
\hline Rest & $34.2(2.4)$ & $33.4(2.4)$ & $33.8(2.4)$ & 0.7 & 0.9 \\
\hline Continuous & $34.3(1.7)$ & $33.9(2.7)$ & $34.1(2.3)$ & & \\
\hline Mean solution time & & Time/ms (SD) & & & \\
\hline Walk & $7325.5(1925.2)$ & $7829.7(3770.3)$ & $7613.6(3060.5)$ & & \\
\hline Rest & $10098.2(3625.9)$ & 9011.1 (3573) & 9477 (3547.4) & $0.02^{*}$ & 0.5 \\
\hline Continuous & $8331.9(4139.4)$ & $8101.1(2055.2)$ & 8200.1 (3031.6) & & \\
\hline Planning time & & Time/ms (SD) & & & \\
\hline Walk & $5061.7(1566.9)$ & $5599.5(3516.1)$ & $5369(2802.9)$ & & \\
\hline Rest & $7612.2(3454.3)$ & $6407.9(3133.9)$ & $6924(3247.7)$ & $0.04^{*}$ & 0.4 \\
\hline Continuous & $6069.6(3883.9)$ & $5707.5(1961.3)$ & $5862.7(2860.7)$ & & \\
\hline \multicolumn{2}{|c|}{ RPE following gameplay } & 6-20 Borg & & & \\
\hline Walk & $12.3(4)$ & $13.1(2.9)$ & $12.8(3.3)$ & & \\
\hline Rest & $11.6(4.3)$ & $11.3(2.6)$ & $11.4(3.3)$ & 0.08 & 0.8 \\
\hline Continuous & $12.9(2.1)$ & $13.4(2.9)$ & $13.2(2.5)$ & & \\
\hline \multicolumn{2}{|c|}{ Reaction time incongruent trials } & Time/ms (SD) & & & \\
\hline Walk & $642.1(99.9)$ & $683.3(99.4)$ & 665.6 (99.3) & & \\
\hline Rest & $944.4(601.4)$ & $761.4(192.7)$ & $840(416.8)$ & 0.07 & 0.4 \\
\hline Continuous & $748(127.3)$ & $684.9(191.7)$ & $712(166.5)$ & & \\
\hline \multicolumn{2}{|l|}{ Proportion correct } & $\%$ (SD) & & & \\
\hline Walk & $92(6.0)$ & $93(6.0)$ & $92(6.0)$ & & \\
\hline Rest & $90(6.0)$ & $92(5.0)$ & $92(5.0)$ & 0.6 & 0.7 \\
\hline Continuous & $91(6.0)$ & $90(8.0)$ & $91(7.0)$ & & \\
\hline \multicolumn{2}{|l|}{ Kill/death ratio } & KDR (SD) & & & \\
\hline Walk & $2.0(1.2)$ & $2.8(2.3)$ & $2.5(2.0)$ & & \\
\hline Rest & $1.9(1.2)$ & $2.6(2.2)$ & $2.3(1.9)$ & 0.8 & 0.5 \\
\hline Continuous & $2.1(1.2)$ & $2.2(1.6)$ & $2.2(1.4)$ & & \\
\hline \multicolumn{2}{|c|}{ Percentage of games won } & $\%$ (SD) & & & \\
\hline Walk & $40.2(27.7)$ & $65.4(20.1)$ & $53.8(26.4)$ & & \\
\hline Rest & $38.3(37.1)$ & $51.1(35.5)$ & $45.2(35.3)$ & 0.6 & 0.4 \\
\hline Continuous & $53.5(10.1)$ & 53 (18.7) & $53.2(14.7)$ & & \\
\hline
\end{tabular}

${ }^{*}$ Significance.

RPE, rate of perceived exertion. 
Table 3 Participants' perception data on each condition

\begin{tabular}{|c|c|c|c|c|}
\hline $\begin{array}{l}\text { Positively } \\
\text { helped (\%) }\end{array}$ & $\begin{array}{l}\text { Negatively } \\
\text { impacted (\%) }\end{array}$ & No impact (\%) & $\begin{array}{l}\text { Representative positively helped } \\
\text { comment: }\end{array}$ & $\begin{array}{l}\text { Representative negatively } \\
\text { impacted comment: }\end{array}$ \\
\hline 73.9 & 8.7 & 17.4 & $\begin{array}{l}\text { 'It was good to take a break, but I think } \\
\text { its active nature helped me stay prepared } \\
\text { physically while offering me a more mental } \\
\text { break.' }\end{array}$ & $\begin{array}{l}\text { 'It was a light movement and didn't } \\
\text { fatigue me, but did break focus on } \\
\text { the game.' }\end{array}$ \\
\hline
\end{tabular}

\section{How do you believe the 6 min rest break impacted your gaming performance?}

$39.1 \quad 26.1 \quad 34.8$

'I treated it like meditation! I focused and 'While the 6 -minute rest itself reflected on the previous games to try and felt great, when I got back to my prepare myself better for the following ones.'

computer, I felt slow and lethargic, and it took me a while to get back into the game and warmup again.'

\begin{tabular}{|c|c|c|c|c|c|}
\hline $\begin{array}{l}\text { Walking } \\
\text { break (\%) }\end{array}$ & $\begin{array}{l}\text { Rest break } \\
(\%)\end{array}$ & $\begin{array}{l}\text { Continuous } \\
\text { play }(\%)\end{array}$ & $\begin{array}{l}\text { No difference } \\
(\%)\end{array}$ & $\begin{array}{l}\text { Representative walking break } \\
\text { preference comments: }\end{array}$ & $\begin{array}{l}\text { Representative rest break } \\
\text { preference comment: }\end{array}$ \\
\hline \multirow[t]{3}{*}{52.2} & \multirow[t]{3}{*}{21.7} & \multirow[t]{3}{*}{21.7} & \multirow[t]{3}{*}{4.3} & $\begin{array}{l}\text { 'I can't tell exactly why, but physically } \\
\text { moving my body helped me feel more } \\
\text { refreshed when I started the game again } \\
\text { vs when I rested on my bed.' }\end{array}$ & $\begin{array}{l}\text { 'The lying down rest allowed me to } \\
\text { more quickly relax after being fairly } \\
\text { tense during play, which made the } \\
\text { 'mental reset' feel more impactful on } \\
\text { [future] play.' }\end{array}$ \\
\hline & & & & \multirow{2}{*}{$\begin{array}{l}\text { '(The] walking break definitely has the best } \\
\text { impact on gaming performance. It helps } \\
\text { you clear your mind while doing something } \\
\text { physical. Even if you are walking slowly, it } \\
\text { helps you calm down and forget the high } \\
\text { pressure from the gaming environment. } \\
\text { Your brain isn't going overboard anymore.' }\end{array}$} & $\begin{array}{l}\text { Representative continuous play } \\
\text { preference comment: }\end{array}$ \\
\hline & & & & & $\begin{array}{l}\text { 'No break allows [you] to stay in the } \\
\text { zone and keeps you warmed up. Pro } \\
\text { esports players have been caught } \\
\text { taking Adderall so that they can stay } \\
\text { in-game longer. Dedicating the most } \\
\text { amount of time possible is the only } \\
\text { way to get better at a game. It [is] } \\
\text { exactly like a real sport,' }\end{array}$ \\
\hline
\end{tabular}

performance. Most commonly noted was the walk provided a good mental break, while half commented on its effectiveness of being physically active.

Responses were more varied regarding whether participants perceived the $6 \mathrm{~min}$ laying down rest break impacted gaming performance as under $40 \%$ felt it positively helped. Participants who perceived that the rest break negatively hurt performance commonly noted that the rest made them sleepy, lethargic and slowed them.

When asked, 'Which of the following do you think is most effective to help gaming performance?' over half preferred the walking break. Common themes across participants who favoured the walking break perceived that the walk helped them provide an active break for their body and mind while at the same time physically preparing them for the next gaming session. Participants who favoured no break felt this helped keep in-game focus and consistent performance, with multiple participants noting that many professional esports players take Adderall for this very purpose. Adderall (generic name: amphetamine, dextroamphetamine mixed salts) is a prescription medication that belongs to a class of drugs known as central nervous system stimulants. It is typically prescribed to treat symptoms of attention deficit and hyperactivity disorder (ADHD) and impulse control. In people who do not suffer from ADHD, it produces excess dopamine in the brain that can create increased energy levels and euphoria. Recreation abuse can lead to dangerous health effects ${ }^{22}$ (table 3 ).

\section{DISCUSSION}

This study was conducted virtually due to the lockdown regulations imposed globally from the COVID-19 pandemic during July through December 2020, comparing a $6 \mathrm{~min}$ active break, a $6 \mathrm{~min}$ passive break and no break on competitive FPS player performance and executive function. It is the first to demonstrate that an active break improves executive function compared with a passive (ie, rest) break while not impacting game performance. Interestingly, the continuous play (no break) performed superior to the resting break. Hence, a resting break may be a detriment to esports players.

The complexity and fast-paced demands of FPS gameplay place a significant demand on attention, cognition, working memory and executive function. ${ }^{12}$ In gaming, on a neural basis, elite esports players demonstrate enhanced cognitive control and attention. ${ }^{2} 23$ These cognitive demands elicit a sympathetic nervous system response presented by heart rate variability, heart rate fluctuations, respiratory rate increases, ventilation changes and blood pressure changes. ${ }^{311}$ This type of 
demand may lead to mental fatigue, cognitive decline and, possibly, poor performance over time.

This project studied FPS gamers ranked at a highly competitive level. FPS games require rapid speed and reaction time, fine motor hand-eye coordination and demand high amounts of executive function and simultaneous actions. ${ }^{3}$ FPS gameplay also facilitates HR variability, HR fluctuations and increased cortisol levels. ${ }^{1311}$ Finally, 2 hours of continuous esports gameplay have resulted in less accuracy and more impulsivity. ${ }^{11}$ Given the cognitive demands required for high-level esports and the multiple hours of being seated, it is of interest to players and health professionals to incorporate practical ways to improve on performance while also improving health. To date, there are no studies that have comprehensively evaluated the physiological parameters in gamers. Therefore, the mechanisms described below of the underlying effects of prolonged sitting are based on previous studies in other populations and have been well established.

\section{Cerebral blood flow and prolonged sitting}

The middle cerebral artery (MCA) accounts for $70 \%-80 \%$ of the brain's perfusion. In healthy individuals who were not gamers, uninterrupted sitting for 4 hours caused a significant decrease in MCA blood flow velocity to $1.4-3.2 \mathrm{~cm} / \mathrm{s}$. $^{10}$ This may not seem relevant, but this decline has been correlated to decreased focus and fatigue. Simply taking a 2 min light walking break every $30 \mathrm{~min}$ prevented these declines and improved cerebral autoregulation. ${ }^{10}$ Moreover, Wennberg et al found that $3 \mathrm{~min}$ of light walking, following $30 \mathrm{~min}$ of being seated, reduced fatigue and improved cognition in overweight adults. ${ }^{13}$ Although we were unable to collect biological variables in this study, we demonstrated an improvement in decision-making and impulsivity following a $6 \mathrm{~min}$ light walking break at the 60 min marker.

\section{Endothelial function and prolonged sitting}

Thrombolytic events are concern in gamers despite age or activity level. ${ }^{5} 7$ The underpinning mechanism resulting in DVTs is endothelial function changes and blood flow, resulting from bouts of prolonged sitting. Following 1 hour of sitting, there is a significant reduction in superficial femoral artery flow-mediated dilation and a decrease in popliteal flow-mediated dilation that can last up to 3 hours or more. ${ }^{24}$ Furthermore, endothelial changes and blood volume changes create an environment that can create blood pooling and more dangerous DVTs or PE. However, these blunted and vascular impairments caused by prolonged sitting were reversed with very light short bouts of activity. ${ }^{25}$

\section{Exercise intensity}

De Las Heras et al exercised gamers using HIIT for $15 \mathrm{~min}$ at an RPE of 15.17 (0.34), which translates to working 'hard' or 'heavy'. ${ }^{26}$ The average RPE for participants in the walking condition in this study was 10.5 (2.8), which translates to 'light' intensity effort. Interestingly, the RPE for gaming was higher than the RPE for the walking break. The average perceived intensity level of gameplay was 13.5 (1.2), which is 'somewhat hard', further demonstrating the perceived demands of gaming. ${ }^{18}$ This study demonstrated improvement in cognitive abilities with as little as $6 \mathrm{~min}$ of light movement. Additionally, $73.9 \%$ of participants perceived that the active walking break positively helped their gaming performance. Based on the results of the IPAQ there was no relationship between physical activity level and preference for a walking break.

\section{Limitations}

There are several limitations to this study. To collect data during the lockdowns of a pandemic, compromises had to be made. Collecting valid objective biometric data proved to be difficult and not feasible. Therefore, the walking effort was determined using the Borg RPE scale. Although this scale is validated, self-report bias may exist. The nature of the online data collection may have impacted how subjects conducted the tests without being in a testing environment. However, this is more reflective of a typical gaming environment than conducting the tests in a lab, which may have increased external validity. Results indicated no study intervention arm significantly impacted player win/loss rate or KDR. Still, other extraneous factors may also impact this (eg, quality of opponent or teammate gameplay, varying maps across games etc). Although there were no executive function changes seen between genders, the physiological changes from prolonged gaming while improving executive function could not be tested in this cohort.

\section{CONCLUSION}

This study has several implications. First, gaming performance and executive function were investigated in relation to an active $6 \mathrm{~min}$ break and a passive $6 \mathrm{~min}$ break, compared with continuous gameplay. While either intervention did not impact gaming performance, the active break showed an increase in speed with no change in accuracy, whereas the passive break had no change. Continuous play was slightly better than the resting break. Second, this is the first study to compare competitive gamers by gender in terms of executive function and gaming performance. Finally, this study showed the efficacy of conducting a virtual clinical trial. This is important in the gaming environment for a few reasons: (1) many investigators do not have easy physical access to esports players and (2) in cases of a pandemic or social distancing, there are valid and effective tools that can be used to assess outcomes virtually.

There have been several calls for improving gamers' health, with exercise being the primary focus. ${ }^{26-29}$ However, there may be a fair misconception that if one exercises regularly, one is not prone to negative health ramifications of prolonged sitting. Being less sedentary with frequent breaks may have a greater health impact than increasing exercise. ${ }^{8}$ This study provides evidence 
that a 6 min walking break improved executive function following a single bout of prolonged gaming and that an active break was preferred compared with a resting break. These findings suggest further investigation into multiple bouts of prolonged gaming to further understand the long-term implications an active break may have in competitive gamers.

\section{Author affiliations}

${ }^{1}$ Department of Osteopathic Medicine, New York Institute of Technology College of Osteopathic Medicine, Old Westbury, New York, USA

${ }^{2}$ Department of Exercise \& Rehabilitative Sciences, Slippery Rock University of Pennsylvania, Slippery Rock, Pennsylvania, USA

${ }^{3}$ New York Institute of Technology School of Health Professions, Old Westbury, New York, USA

${ }^{4}$ New York Institute of Technology College of Osteopathic Medicine, Old Westbury, New York, USA

Twitter Joanne DiFrancisco-Donoghue @NYITsportsmed; @JerryBalentine; @ joannedonoghue4

Contributors JD-D, SEJ, PD, AS, SA, KY, TH, HG, KA contributed to the design and implementation of the research, to the analysis of the results and to the writing of the manuscript

Funding The authors have not declared a specific grant for this research from any funding agency in the public, commercial or not-for-profit sectors.

Competing interests None declared.

Patient consent for publication Not required.

Ethics approval This study was approved by the NYIT Institutional Review Board.

Provenance and peer review Not commissioned; externally peer reviewed.

Data availability statement Data are available upon reasonable request.

Open access This is an open access article distributed in accordance with the Creative Commons Attribution Non Commercial (CC BY-NC 4.0) license, which permits others to distribute, remix, adapt, build upon this work non-commercially, and license their derivative works on different terms, provided the original work is properly cited, appropriate credit is given, any changes made indicated, and the use is non-commercial. See: http://creativecommons.org/licenses/by-nc/4.0/.

ORCID iD

Joanne DiFrancisco-Donoghue http://orcid.org/0000-0002-0848-3022

\section{REFERENCES}

1 Toth AJ, Ramsbottom N, Kowal M, et al. Converging evidence supporting the cognitive link between exercise and Esport performance: a dual systematic review. Brain Sci 2020;10:859.

2 Kowal M, Toth AJ, Exton C. Different cognitive abilities displayed by action video gamers and non-gamers. computers and human behaviors. Comput Hum Behav 2018;88:255-62.

3 Koshy A, Cironis L, McVey M. An observation of common physiological parameters during esports activity. International Journal of Esports 2020;1.

4 Bediou B, Adams DM, Mayer RE, et al. Meta-Analysis of action video game impact on perceptual, attentional, and cognitive skills. Psychol Bull 2018;144:77-110.

5 Lippi G, Mattiuzzi C, Favaloro EJ. e-thrombosis: epidemiology, physiopathology and rationale for preventing computer-related thrombosis. Ann Trans/ Med 2018;6:344.

6 Chang $\mathrm{H}-\mathrm{CL}$, Burbridge $\mathrm{H}$, Wong $\mathrm{C}$. Extensive deep vein thrombosis following prolonged gaming ('gamer's thrombosis'): a case report. $J$ Med Case Rep 2013;7.
7 Beasley R, Raymond N, Hill S, et al. eThrombosis: the 21st century variant of venous thromboembolism associated with immobility. Eur Respir J 2003;21:374-6.

8 Ekelund U, Steene-Johannessen J, Brown WJ, et al. Does physical activity attenuate, or even eliminate, the detrimental association of sitting time with mortality? A harmonised metaanalysis of data from more than 1 million men and women. Lancet 2016;388:1302-10.

9 Latouche C, Jowett JBM, Carey AL, et al. Effects of breaking up prolonged sitting on skeletal muscle gene expression. J Appl Physiol 2013;114:453-60.

10 Carter SE, Draijer R, Holder SM, et al. Regular walking breaks prevent the decline in cerebral blood flow associated with prolonged sitting. J Appl Physiol 2018;125:790-8.

11 Sousa A, Ahmad SL, Hassan T, et al. Physiological and cognitive functions following a discrete session of competitive Esports gaming. Front Psychol 2020;11:1030.

12 Dogra S, Wolf M, Jeffrey MP, et al. Disrupting prolonged sitting reduces IL-8 and lower leg swell in active young adults. BMC Sports Sci Med Rehabil 2019;11:23.

13 Wennberg P, Boraxbekk C-J, Wheeler M, et al. Acute effects of breaking up prolonged sitting on fatigue and cognition: a pilot study. BMJ Open 2016;6:e009630-2015-009630.

14 Harris PA, Taylor R, Thielke R, et al. Research electronic data capture (REDCap)--a metadata-driven methodology and workflow process for providing translational research informatics support. J Biomed Inform 2009;42:377-81.

15 Portney LG. Foundations of clinical research: applications to evidence-based practice. Fourth edition. Philadelphia: F.A. Davis, 2020: 235.

16 Chrismas BCR, Taylor L, Cherif A, et al. Breaking up prolonged sitting with moderate-intensity walking improves attention and executive function in Qatari females. PLoS One 2019;14:e0219565.

17 Hagströmer M, Oja P, Sjöström M. The International physical activity questionnaire (IPAQ): a study of concurrent and construct validity. Public Health Nutr 2006;9:755-62.

18 Pollock BS, Barkley JE, Potenzini N, et al. Validity of Borg ratings of perceived exertion during active video game play. Int $J$ Exerc Sci 2013;6:164-70

19 Scarpina F, Tagini S. The Stroop color and word test. Front Psychol 2017;8:557.

20 Kafer KL, Hunter M. On testing the face validity of planning/problemsolving tasks in a normal population. J Int Neuropsychol Soc 1997;3:108-19

21 Creswell J, Poth C. Qualitative inquiry and research design: choosing among five approaches. 4th ed. Sage Publications, Inc, 2018.

22 Heal DJ, Smith SL, Gosden J, et al. Amphetamine, past and present-a pharmacological and clinical perspective. J Psychopharmacol 2013;27:479-96.

23 Palaus M, Marron EM, Viejo-Sobera R, et al. Neural basis of video gaming: a systematic review. Front Hum Neurosci 2017;11:248.

24 Thosar SS, Bielko SL, Wiggins CC, et al. Differences in brachial and femoral artery responses to prolonged sitting. Cardiovasc Ultrasound 2014;12:50

25 Restaino RM, Walsh LK, Morishima T, et al. Endothelial dysfunction following prolonged sitting is mediated by a reduction in shear stress. Am J Physiol Heart Circ Physiol 2016;310:H648-53.

26 DE Las Heras B, Li O, Rodrigues L, et al. Exercise improves video game performance: a win-win situation. Med Sci Sports Exerc 2020;52:1595-602.

27 DiFrancisco-Donoghue J, Werner WG, Douris PC, et al. Esports players, got muscle? competitive video game players' physical activity, body fat, bone mineral content, and muscle mass in comparison to matched controls. J Sport Health Sci 2020:S2095254620300934.

28 DiFrancisco-Donoghue J, Balentine J, Schmidt G, et al. Managing the health of the eSport athlete: an integrated health management model. BMJ Open Sport Exerc Med 2019;5:e000467.

29 Zwibel H, DiFrancisco-Donoghue J, DeFeo A, et al. An osteopathic physician's approach to the Esports athlete. J Am Osteopath Assoc 2019;119:756-62. 